\title{
Bean golden yellow mosaic virus from Chiapas, Mexico: Characterization, Pseudorecombination with Other Bean-Infecting Geminiviruses and Germ Plasm Screening
}

\author{
E. R. Garrido-Ramirez, M. R. Sudarshana, and R. L. Gilbertson
}

Department of Plant Pathology, University of California, Davis 95616.

Current address of E. R. Garrido-Ramirez: INIFAP, Campo Experimental Centro de Chiapas, Apdo. Postal \#1 Ocozocoautla, Chis. C.P. 29140, Mexico.

Accepted for publication 4 August 2000.

\begin{abstract}
Garrido-Ramirez, E. R., Sudarshana, M. R., and Gilbertson, R. L. 2000. Bean golden yellow mosaic virus from Chiapas, Mexico: Characterization, pseudorecombination with other bean-infecting geminiviruses, and germ plasm screening. Phytopathology 90:1224-1232.

The complete nucleotide (nt) sequences of the cloned DNA-A (2644 nts) and DNA-B (2609 nts) components of Bean golden yellow mosaic virus (BGYMV-MX) from Chiapas, Mexico were determined. The genome organization of BGYMV-MX is similar to that of other Western Hemisphere bipartite geminiviruses (genus Begomovirus). Infectivity of the cloned BGYMV-MX DNA components in common bean (Phaseolus vulgaris) plants was demonstrated by particle bombardment and agroinoculation. BGYMV-MX was identified as a BGYMV (previously type II BGMV) isolate based on sequence analyses, sap-transmissibility, and pseudorecombination experiments with other bean-infecting begomo-

viruses. On the basis of differences in the DNA-B hypervariable region, symptom phenotype, and properties of infectious pseudorecombinants, BGYMV-MX may represent a distinct strain of BGYMV. Pseudorecombination experiments further established that BGYMV symptom determinants mapped to DNA-B, and that BGYMV-MX was most closely related to BGYMV from Guatemala. A Tomato leaf crumple virus (TLCrV) DNA-A/BGYMV-MX DNA-B pseudorecombinant was infectious in bean, establishing that a viable reassortant can be formed between begomovirus species from different phylogenetic clusters. Bean germ plasm representing the two major gene pools (Andean and Mesoamerican) was screened for response to BGYMV-MX with three methods of inoculation: sap-inoculation, particle bombardment, and agroinoculation. Andean germ plasm was very susceptible and similar results were obtained with all three methods, whereas Mesoamerican germ plasm showed resistance to BGYMV-MX, particularly with agroinoculation.
\end{abstract}

Bean golden mosaic is a severe disease of common bean (Phaseolus vulgaris L.) in tropical and subtropical areas of America and the Caribbean Basin, where this crop constitutes a major component of dietary protein. Symptoms of bean golden mosaic include a striking green-yellow mosaic on leaves and stunted and distorted plant growth. Yield losses can reach $100 \%$ if plants are infected early in development (10); however, disease incidence and the extent of losses vary depending on populations of the whitefly vector (Bemisia tabaci Genn.), environmental conditions, and cultural practices.

Golden mosaic disease of bean was first reported in Brazil in 1961 (6) and later from Central America and the Caribbean Basin $(7,10,14)$. More recently, the disease was reported in southern Florida, where it has caused significant losses to snap bean production (1). In Mexico, the state of Chiapas is an important bean production area and, over the last 10 years, golden mosaic has become the most important disease in this state.

The causal agent of bean golden mosaic is Bean golden mosaic virus (BGMV), the type member of the genus Begomovirus (family Geminiviridae). Begomoviruses are transmitted by whiteflies, infect dicotyledonous plants, and possess a monopartite or bipartite genome $(3,18,33)$. The bipartite genome is composed of two $\approx 2.6-\mathrm{kb}$ circular single-stranded DNA molecules (DNA-A and

Corresponding author: R. L. Gilbertson; E-mail address: rlgilbertson@ucdavis.edu

Nucleotide sequence data can be found in GenBank as Accession Nos. AF173555 (DNA-A) and AF173556 (DNA-B).

Publication no. P-2000-0905-01R

(C) 2000 The American Phytopathological Society
DNA-B) that are individually encapsidated into $18 \times 30 \mathrm{~nm}$ twinned icosahedral virus particles. The DNA-A and DNA-B components of a begomovirus species share $\mathrm{a} \approx 200$ nucleotide (nt) sequence referred to as the common region $(\mathrm{CR})$ that contains the viral origin of replication $(3,18,33)$. DNA-A encodes genes involved in replication, gene expression, and encapsidation, whereas DNA-B encodes genes involved in viral movement. Both components are required for efficient infection $(18,33)$.

Studies of begomoviruses associated with bean golden mosaic from different geographical regions have revealed that two distinct begomovirus species that differ in nucleotide sequence and biological properties cause bean golden mosaic (13). However, because these viruses induce very similar disease symptoms, they were named BGMV type I and II (13). Type I BGMV isolates are found in South America (Brazil) and are not sap-transmissible $(6,8,13)$, whereas type II isolates are found in Central America, the Caribbean Basin, and Florida, and are readily sap-transmissible $(1,7,24)$. The nomenclature of BGMV was recently revised to provide distinct species names for types I and II BGMV: Type I BGMVs (e.g., BGMV from Brazil [BGMV-BZ]; 13) retain the name BGMV based on the disease being first described from Brazil (6). Type II BGMVs (e.g., BGMVs from Guatemala [BGMV-GA], Puerto Rico [BGMV-PR], and the Dominican Republic [BGMV-DR]; 7,24) were renamed Bean golden yellow mosaic virus (BGYMV), which was the name first given to type II BGMV from Puerto Rico (2).

Common bean can also be infected under natural conditions by other begomoviruses such as Bean dwarf mosaic virus (BDMV; 28 ) and Bean calico mosaic virus (BCMoV; 4). Under experimental conditions, many begomoviruses can infect common bean, including Squash leaf curl virus (SLCV; 25), Tomato leaf crumple virus (TLCrV; 30), and Sida golden mosaic virus (SiGMV; 9). 
Bean golden mosaic is a very difficult disease to control, and the development and use of resistant cultivars is the most desirable approach for disease management, particularly for small farmers in less developed countries. Common bean germ plasm has been extensively screened for resistance to golden mosaic caused by BGYMV, and resistance was found in small-seeded black beans of the Mesoamerican gene pool (27). Additional sources of resistance have also been identified in several nonblack seeded varieties (29).

This study was conducted to characterize on the molecular level the begomovirus causing bean golden mosaic in Chiapas, Mexico and to determine the relationship of this begomovirus with other previously characterized bean-infecting begomoviruses. An agroinoculation system was developed for this begomovirus, and three inoculation methods (sap-transmission, particle bombardment, and agroinoculation) were compared for assessing bean golden mosaic resistance in common bean.

\section{MATERIALS AND METHODS}

Virus source and sap transmission. Bean leaves with golden mosaic symptoms were collected from four commercial fields in Chiapas, Mexico in August 1995. Sap inoculation of common bean (cv. Topcrop) seedlings was carried out as previously described (15). Briefly, inoculum (sap) was prepared by grinding infected trifoliolate leaves in ice-cold $0.1 \mathrm{M}$ potassium phosphate buffer $(\mathrm{pH} 8.0)$ at a 1:5 (wt/vol) ratio in a mortar and pestle. The sap was rub-inoculated with the pestle onto celite-dusted one-half to three-quarters expanded primary leaves of common bean (cv. Topcrop) or leaves of Nicotiana benthamiana plants at the 5 to 7 leaf stage of growth. Plants were maintained in a controlled environment chamber $\left(250 \mu \mathrm{mol} \mathrm{m} \mathrm{m}^{-2}, 16 \mathrm{~h}\right.$ per day, $\left.30^{\circ} \mathrm{C}\right)$, and symptoms were recorded 10 to 14 days postinoculation (dpi).

Squash blot hybridization. Geminivirus nucleic acids were detected in plant tissues by squash blot hybridization as previously described (15). The probe was a mixture of full-length DNA-A and DNA-B components of BGMV-BZ and BGYMV-GA, labeled with $\left[\alpha-{ }^{32} \mathrm{P}\right] \mathrm{dCTP}$ by nick translation according to manufacturer's recommendations (BRL, Gaithersburg, MD).

DNA extraction and polymerase chain reaction. Extraction of DNA for polymerase chain reaction (PCR), and PCR conditions used to amplify geminivirus DNA fragments have been previously described (17,32). Amplification of geminivirus DNA fragments was directed by the degenerate PCR primer pairs PAL1v1978/ PAR1c496 for DNA-A, and PBL1v2040/PCRc1 for DNA-B (32). PCR-amplified DNA fragments were visualized by electrophoresis in $0.7 \%$ agarose gels in $0.5 \times$ Tris-borate-EDTA buffer.

Cloning and sequencing of PCR-amplified DNA fragments. PCR-amplified DNA fragments were excised from $1 \%$ agarose gels in Tris-acetate-EDTA buffer, recovered with silica matrix (Bio101 Inc., Vista, CA) and cloned with the TA cloning system (Invitrogen, Carlsbad, CA). The nucleotide sequences of selected cloned DNA fragments were determined for both strands by the dideoxynucleotide chain-termination method and Sequenase (United States Biochemical Corp., Cleveland) according to the manufacturer's instructions. Sequences were compiled, analyzed, and compared using the software of the Genetics Computer Group (University of Wisconsin, Madison).

Cloning and characterization of viral dsDNA. To obtain fulllength clones, a DNA preparation enriched for geminiviral DNAs was made from infected leaf and stem tissues (14). This DNA was digested with SpeI and ligated into SpeI-digested pBluescript KS(+) (Stratagene, La Jolla, CA). Recombinant plasmids having the expected-size insert $(\approx 2.6 \mathrm{~kb})$ were identified by restriction enzyme digestion analysis. The infectivity of putative full-length clones was determined by particle bombardment of excised linear double-stranded (ds) monomers into common bean seedlings (cv. Topcrop) as previously described (30). Seedlings were planted in soil and maintained in a growth chamber as previously described. Symptom development was recorded $10 \mathrm{dpi}$. In selected plants, the presence of the virus was confirmed by amplification of the expected 1.1-kb DNA-A and 0.5-kb DNA-B fragments with the degenerate primer pairs PAL1v1978/PAR1c496 and PBL1v2040/ PCRc1, respectively.

Sequence and phylogenetic analyses. DNA sequencing of the infectious BGYMV-MX DNA-A (in plasmid pBGMXA1) and DNA-B (in plasmid pBGMXB1) components was carried out as previously described. Nucleotide sequence identities and amino acid identities and similarities were determined using GAP. Nucleotide sequences were aligned with PILEUP, and phylogenetic analyses were carried out with Phylogenetic Analysis Using Parsimony (PAUP) Version 4.0 beta (Sinauer Associates Inc., Sunderland, MA). Optimum trees and branch strengths were determined as previously described (7). The following geminivirus sequences were used for comparisons and phylogenetic analyses: African cassava mosaic virus isolates from Kenya (J02057 and J02058); Abutilon mosaic virus (AbMV; X15983 and X15984); BCMoV (AF110189 and AF110190); BGMV-BZ (M88686 and M88687); BGYMV-PR (M10070 and M10080); BGYMV-GA (M91604 and M91605); BGYMV-DR (L01635 and L01636); BDMV (M88179 and M88180); Mung bean yellow mosaic virus (D14703 and D14704); Pepper huasteco virus (X70418 and X70419); Potato yellow mosaic virus (D00940 and D00941); SLCV (M38183 and M38182); Tomato golden mosaic virus (K02029 and K02030); Tomato mottle virus (ToMoV; L14460 and L14461); TLCrV (AF101476 and AF101478); and SiGMV; (X99550 and X99551).

Production of multimeric clones of BGYMV-MX DNA-A and DNA-B. Recombinant plasmids containing multimeric copies (1.6 to 1.7-mers) of BGYMV-MX DNA-A and DNA-B were generated according to the approach described by Paplomatas et al. (30). However, because the cloning site (SpeI) of the BGYMVMX DNA-A and DNA-B monomers was in the CR, it was first necessary to reclone both components in order to generate multimeric clones having two complete CR sequences. Thus, BGYMV-MX DNA-A (from clone pBGMXA1) and DNA-B (from clone $\mathrm{pBGMXB1}$ ) were recloned in $\mathrm{pKS}$ digested with EcoRI and Sst I, respectively, to generate pBGMXA2 and pBGMXB2.

For BGYMV-MX DNA-A, pBGMXA2 was double-digested with $B a m \mathrm{HI}$ and $B g l \mathrm{II}$ to release a $\approx 0.8-\mathrm{kb}$ DNA-A fragment that included one of the EcoRI cloning sites. The remaining $4.7-\mathrm{kb}$ $B a m \mathrm{HI} / B g l \mathrm{II}$ fragment was gel-purified and religated. This recombinant plasmid (pBGMXA0.7) contained a $\approx 1.8$-kb DNA-A fragment $(\approx 0.7$-mer $)$ that included the complete $\mathrm{CR}$ and a single $E c o$ RI site. The full-length EcoRI DNA-A fragment from pBGMXA2 was ligated into EcoRI-digested pBGMXA0.7 to generate pBGMXA1.7, which contains a 1.7-mer of the BGYMVMX DNA-A component.

For BGYMV-MX DNA-B, pBGMXB2 was digested with HindIII to release $\mathrm{a} \approx 0.9-\mathrm{kb}$ DNA-B fragment that included one of the SstI cloning sites. The remaining 4.6-kb HindIII fragment was gel-purified and religated. This recombinant plasmid (pBGMXB0.6) contained $\mathrm{a} \approx 1.6-\mathrm{kb}$ DNA-B fragment $(\approx 0.6$-mer) that included the complete CR and a single SstI site. The full-length SstI DNAB fragment from pBGMXB2 was ligated into SstI-digested pBGMXB0.6 to generate pBGMXB1.6, which contains a $\approx 1.6$-mer of the BGYMV-MX DNA-B component. Infectivity of selected multimeric DNA-A and DNA-B clones in bean seedlings (cv. Topcrop) was established by particle bombardment as described (30).

Development of a BGYMV-MX agroinoculation system. Plasmids pBGMXA1.7 and pBGMXB1.6 were linearized with $X b a \mathrm{I}$ and individually cloned into the binary vector pCGN1547 (26) to generate pBGMXAbin and pBGMXBbin, respectively. Agrobacterium tumefaciens LBA4404 was transformed with these recombinant plasmids, and transformants were identified by PCR analysis with degenerate DNA-A and DNA-B primers, re- 
spectively (23). One Agrobacterium strain containing plasmid pBGMXAbin (DNA-A strain) and one containing plasmid pBGMXBbin (DNA-B strain) were used for agroinoculation experiments. Ten-day-old bean seedlings were agroinoculated with a mixture of DNA-A and DNA-B Agrobacterium cell suspensions by needle puncture-injection of the first internode (the point of attachment of the primary leaves) (23). Agroinoculated plants were maintained in a growth chamber, and symptoms were recorded 14 dpi.

Pseudorecombination experiments. Pseudorecombination experiments were performed by mixing infectious DNA-A and DNA-B clones of selected begomovirus strains/species (BGYMVMX, BGYMV-GA, BGYMV-DR, BDMV, and TLCrV) and inoculating common bean and $N$. benthamiana plants by particle bombardment (beans) or agroinoculation (beans and N. benthamiana) (23). Inoculated and control plants were maintained in a growth chamber, and symptoms were recorded 14 dpi. Viral DNA was detected in selected inoculated and control plants by PCR with degenerate geminivirus primer pairs (PAL1v1978/PAR1c496 for DNA-A and PBL1v2040/PBV1c970 for DNA-B) (12,32). In selected plants, the presence of the inoculated DNA components was confirmed by restriction enzyme digestion analysis of PCRamplified DNA fragments.

Bean germ plasm screening. Three inoculation methods were used to screen bean germ plasm: particle bombardment, sapinoculation, and agroinoculation. For particle bombardment, DNA-A and DNA-B 1.5-mers (plasmids pBGMXA1.7 and pBGMXB1.6) were bombarded into hypocotyls of 48-h-old bean seedlings, whereas for sap-inoculation and agroinoculation, approximately 10-day-old seedlings (primary leaf stage) were inoculated. Inoculated plants were maintained in a growth chamber, and disease symptoms were evaluated $14 \mathrm{dpi}$. The relative resistance or susceptibility was assessed based on BGYMV incidence (i.e., percent infected plants) and severity, which was assessed with a rating system of 1 to 9 , where $1=$ no symptoms and $9=$ severe symptoms (5). With this rating system values of 1 , 2 , and 3 are considered resistant; values of 4, 5, and 6 represent an intermediate reaction; and values of 7, 8, and 9 are susceptible. In selected plants, geminivirus infection was confirmed by PCR analysis with degenerate primers.

\section{RESULTS}

Detection of geminivirus nucleic acids and sap transmission. Geminivirus nucleic acids were detected in bean leaves showing golden mosaic symptoms from each of the four fields in Chiapas by squash blot hybridization with a BGMV/BGYMV DNA probe. Using PCR and degenerate primers, DNA-A (1.1 kb) and DNA-B $(0.6 \mathrm{~kb})$ fragments were amplified from DNA extracts prepared from leaf tissues from each field. In a parallel experiment, 8 of 12 bean seedlings (cv. Topcrop) inoculated with sap prepared from leaves from one of the fields developed golden mosaic and severe leaf distortion in newly emerging trifoliolate leaves. These results established that the golden mosaic symptoms in these bean leaf samples were induced by a sap-transmissible bipartite begomovirus.

Cloning and sequencing of PCR-amplified DNA fragments. The DNA-A and DNA-B fragments amplified from leaf samples from each of the four fields were cloned and sequenced. The DNA-A sequences were 99 to $100 \%$ identical, whereas the DNAB sequences were 98 to $99 \%$ identical. This suggested that the plants from these four fields were infected with the same virus. Therefore, sequences from one field (No. 2) were used to make comparisons with those of other begomoviruses. The DNA-A and DNA-B sequences of the bean-infecting begomovirus from Chiapas were most like those of BGYMV-GA (97 and 92\% identities, respectively), indicating it was an isolate/strain of BGYMV. Thus, it will be referred to as BGYMV-MX.

Within the cloned DNA-B fragment is a 300 to 400-bp hypervariable $(\mathrm{HV})$ region that lies between the initiation codon of the $\mathrm{BC} 1$ open reading frame (ORF) and the beginning ( $5^{\prime}$ end) of the $\mathrm{CR}$ (17). Sequences in this region have been used to differentiate species, strains, and isolates of bean-infecting begomoviruses, including BGYMV (17). The BGYMV-MX HV sequence was 86, 84 , and $77 \%$ identical to those of BGYMV-DR, -GA, and -PR, respectively; and 46, 45, 42, and 39\% identical to $\mathrm{HV}$ sequences of TLCrV, BGMV-BZ, BDMV, and BCMoV, respectively.

Cloning and sequencing of infectious full-length clones. Because of the high level of sequence identity between BGYMV-GA and BGYMV-MX, it was reasoned that a SpeI site in the BGYMVGA CR would also be present in the BGYMV-MX CR. Using this strategy, full-length BGYMV-MX DNA-A (pBGMXA1) and DNA-

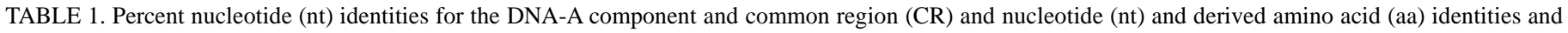

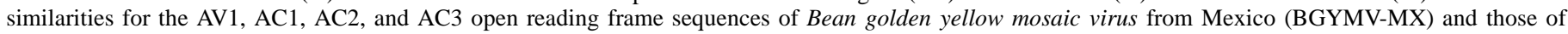
other bipartite begomoviruses ${ }^{\mathrm{a}}$

\begin{tabular}{|c|c|c|c|c|c|c|c|c|c|c|}
\hline \multirow[b]{2}{*}{ Geminivirus } & \multirow[b]{2}{*}{ Total nt } & \multirow[b]{2}{*}{ CR nt } & \multicolumn{2}{|c|}{ AV1 } & \multicolumn{2}{|c|}{$\mathrm{AC} 1$} & \multicolumn{2}{|c|}{$\mathrm{AC} 2$} & \multicolumn{2}{|c|}{ AC3 } \\
\hline & & & $\mathrm{nt}$ & aa & nt & aa & nt & aa & nt & aa \\
\hline BGYMV-GA & 97 & 96 & 98 & 98 (99) & 98 & $98(98)$ & 98 & 97 (97) & 97 & $95(98)$ \\
\hline BGYMV-DR & 97 & 95 & 98 & 99 (99) & 97 & 97 (97) & 99 & $98(98)$ & 98 & $95(98)$ \\
\hline BGYMV-PR & 95 & 93 & 96 & $96(97)$ & 95 & $94(95)$ & 98 & $95(96)$ & 97 & 94 (97) \\
\hline BGMV-BZ & 75 & 65 & 82 & $89(93)$ & 72 & $74(80)$ & 76 & $67(70)$ & 82 & $78(85)$ \\
\hline BDMV & 76 & 72 & 80 & $89(92)$ & 76 & $78(84)$ & 73 & $65(70)$ & 78 & $70(81)$ \\
\hline ToMoV & 76 & 78 & 80 & $88(91)$ & 79 & $81(86)$ & 74 & $65(74)$ & 77 & $76(83)$ \\
\hline AbMV & 75 & 78 & 78 & $86(90)$ & 78 & $76(82)$ & 76 & $67(72)$ & 77 & $76(84)$ \\
\hline SiGMV & 75 & 66 & 81 & $90(92)$ & 76 & $84(84)$ & 78 & $67(74)$ & 78 & $71(81)$ \\
\hline BCMoV & 74 & 55 & 83 & $91(94)$ & 68 & $66(72)$ & 84 & $72(75)$ & 83 & $83(90)$ \\
\hline TLCrV & 74 & 59 & 79 & $89(92)$ & 77 & $81(86)$ & 73 & $66(74)$ & 77 & $73(82)$ \\
\hline PYMV & 74 & 61 & 79 & $90(92)$ & 74 & $74(81)$ & 78 & $72(77)$ & 80 & $77(83)$ \\
\hline TGMV & 73 & 57 & 82 & $92(93)$ & 74 & 73 (79) & 78 & $67(74)$ & 79 & $75(84)$ \\
\hline PHV & 71 & 43 & 81 & $90(92)$ & 68 & $67(75)$ & 68 & $56(64)$ & 72 & $67(74)$ \\
\hline SLCV & 71 & 48 & 83 & $92(94)$ & 64 & $63(69)$ & 82 & 73 (78) & 83 & $82(87)$ \\
\hline ICMV & 63 & 53 & 70 & $82(88)$ & 66 & $66(72)$ & 69 & $55(62)$ & 64 & $55(66)$ \\
\hline MYMV & 61 & 38 & 71 & $79(87)$ & 65 & $62(70)$ & 65 & $45(53)$ & 65 & $40(48)$ \\
\hline ACMV-Ke & 61 & 51 & 65 & $77(85)$ & 64 & $67(74)$ & 67 & $50(57)$ & 67 & $54(62)$ \\
\hline
\end{tabular}

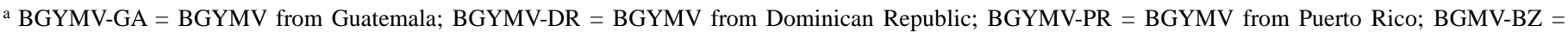
BGMV from Brazil; BDMV = Bean dwarf mosaic virus; $\mathrm{BCMoV}=$ Bean calico mosaic virus; ToMoV = Tomato mottle virus; $\mathrm{AbMV}=$ Abutilon mosaic virus; SiGMV = Sida golden mosaic virus $; \mathrm{TLCrV}=$ Tomato leaf crumple virus $; \mathrm{PYMV}=$ Potato yellow mosaic virus $; \mathrm{TGMV}=$ Tomato golden mosaic virus $; \mathrm{PHV}=$ Pepper huasteco virus; SLCV = Squash leaf curl virus; ICMV = Indian cassava mosaic virus; MYMV = Mung bean yellow mosaic virus; ACMV-Ke = African cassava mosaic virus from Kenya. Total = comparison made with the complete nucleotide sequence of DNA-A. Numbers in parentheses are percent aa similarities. 
B (pBGMXB1) clones were obtained. BGYMV-MX DNA-A is 2644 nt, whereas DNA-B is 2609 nt. Analysis for ORFs encoding proteins $>10 \mathrm{kDa}$ revealed that DNA-A has four such ORFs that correspond to the bipartite begomovirus AV1, AC1, AC2, and AC3 ORFs. An additional DNA-A ORF, encoding a predicted protein of 85 amino acids $(\approx 9.3 \mathrm{kDa})$ corresponds to the AC4 ORF. DNA-B has two ORFs encoding proteins $>10 \mathrm{kDa}$, and these correspond to the BV1 and BC1 ORFs. Thus, the BGYMV-MX genome organization is similar to that described for other Western Hemisphere whitefly-transmitted bipartite begomoviruses $(3,34)$.

The BGYMV-MX DNA-A and DNA-B CRs are 207 and $206 \mathrm{nt}$, respectively, and $93 \%$ identical. This is consistent with these components comprising the genome of a bipartite begomovirus. The BGYMV-MX CR contains the hallmark conserved inverted repeat capable of forming a stem-loop structure, and the loop contains the highly conserved nanonucleotide sequence, TAATATTAC. The CR region also contains two copies of a virus-specific highaffinity binding site that is recognized by the replication-associated (Rep) protein (AC1) (18). The BGYMV-MX highaffinity binding sites are TGGAG, which are identical to those of BGYMV-GA, -DR, and -PR.

Comparisons made between the nucleotide and amino acid sequences of BGYMV-MX and other begomoviruses unequivocally established that BGYMV-MX is a BGYMV isolate/strain (Tables 1 and 2). For example, the complete nucleotide sequence of BGYMV-MX DNA-A was 97, 97, and 95\%, to those of BGYMVGA, -DR, and -PR, respectively, and only $75 \%$ identical to that of BGMV-BZ. The complete nucleotide sequence of BGYMV-MX DNA-B was 92,94 , and $87 \%$, to those of BGYMV-GA, -DR, and -PR, respectively, and only $65 \%$ identical to BGMV-BZ. The close relationship of BGYMV-MX to other BGYMVs is clearly shown by the CR comparisons; the BGYMV-MX DNA-A CR sequence is $\geq 93 \%$ identical to those of other BGYMV isolates and $\leq 70 \%$ identical to CRs of other begomoviruses. Irrespective of the ORF sequence used in the phylogenetic analysis, BGYMV-MX was placed in a BGYMV cluster that included BGYMV-GA, BGYMV-DR, and BGYMV-PR (Figure 1 shows representative phylogenetic trees for the $\mathrm{AC} 1$ and $\mathrm{BC} 1 \mathrm{ORFs})$. The phylogenetic analyses indicated that BGYMV-MX was more closely related to BGYMV-GA than to BGYMV-DR or BGYMV-PR (Fig. 1).
Infectivity of the cloned BGYMV-MX DNA-A and DNA-B. Bean seedlings (cv. Topcrop) bombarded with the full-length BGYMV-MX DNA-A and DNA-B monomers or undigested multimers developed golden mosaic symptoms, whereas seedlings inoculated with gold particles only did not develop symptoms. By 5 to 7 dpi, primary leaves of infected seedlings developed vein yellowing, and by 10 to $14 \mathrm{dpi}$, the first trifoliolate leaves developed golden mosaic symptoms and stunted and distorted growth. Moreover, the golden mosaic symptoms in the trifoliolate leaves were indistinguishable from those observed in the bean leaf samples from Chiapas. Geminivirus DNA-A and DNA-B components were detected in symptomatic plants by PCR. These results established the infectivity of the BGYMV-MX clones.

Bean seedlings (cv. Topcrop) agroinoculated with the BGYMVMX DNA-A and DNA-B developed golden mosaic symptoms in the first trifoliolate leaves $\approx 10$ to $14 \mathrm{dpi}$, whereas mock-inoculated seedlings were symptomless. Approximately $90 \%$ of the agroinoculated seedlings became infected, and symptoms in trifoliolate leaves were indistinguishable from those in infected seedlings inoculated by particle bombardment or sap-inoculation. In contrast to seedlings inoculated by particle bombardment, symptoms did not develop in primary leaves of agroinoculated seedlings. Geminivirus DNA-A and DNA-B components were detected in symptomatic plants by PCR, and not in mock-inoculated plants. These results establish the infectivity of the BGYMV-MX DNA-A and DNA-B components when delivered by A. tumefaciens, and that agroinoculation is an efficient inoculation method.

Pseudorecombination experiments with infectious cloned DNAs of BGYMV-MX and other bean-infecting bipartite begomoviruses. When inoculated into cv. Topcrop by particle bombardment, BGYMV-MX, BGYMV-GA, and BGYMV-DR can be differentiated based on symptomatology in infected trifoliolate leaves. BGYMV-MX induces more extensive chlorosis and stunted and distorted growth compared with BGYMV-GA, which induces larger patches of green tissue, or BGYMV-DR, which induces vein yellowing and chlorotic blotches. BGYMV-MX/ BGYMV-GA pseudorecombinants were highly infectious in bean when inoculated by particle bombardment. All 18 bean seedlings bombarded with BGYMV-MX DNA-A (MX-A) and BGYMVGA DNA-B (GA-B) or BGYMV-GA DNA-A (GA-A) and

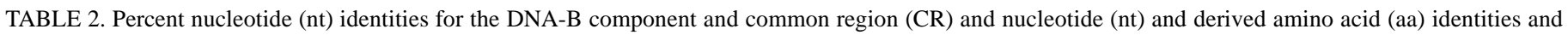

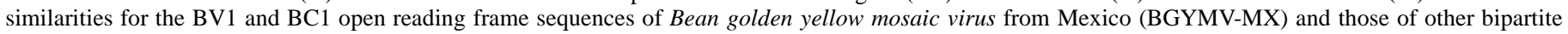
begomoviruses $^{\mathrm{a}}$

\begin{tabular}{|c|c|c|c|c|c|c|}
\hline \multirow[b]{2}{*}{ Geminivirus } & \multirow[b]{2}{*}{ Total nt } & \multirow[b]{2}{*}{ CR nt } & \multicolumn{2}{|c|}{ BV1 } & \multicolumn{2}{|c|}{ BC1 } \\
\hline & & & nt & aa & $\mathrm{nt}$ & aa \\
\hline BGYMV-GA & 92 & 88 & 93 & $93(94)$ & 97 & 99 (99) \\
\hline BGYMV-DR & 94 & 91 & 97 & 97 (97) & 97 & 99 (99) \\
\hline BGYMV-PR & 87 & 86 & 92 & $94(95)$ & 91 & $94(96)$ \\
\hline BGMV-BZ & 65 & 55 & 71 & $71(77)$ & 76 & $81(87)$ \\
\hline BDMV & 66 & 74 & 72 & $73(79)$ & 77 & $86(87)$ \\
\hline ToMoV & 66 & 77 & 72 & $70(76)$ & 75 & $83(89)$ \\
\hline TLCrV & 66 & 58 & 70 & $70(77)$ & 78 & $80(85)$ \\
\hline SiGMV & 66 & 73 & 71 & $72(77)$ & 77 & $85(91)$ \\
\hline AbMV & 65 & 78 & 69 & $75(75)$ & 76 & $63(66)$ \\
\hline TGMV & 65 & 53 & 73 & $70(75)$ & 76 & $84(89)$ \\
\hline BCMoV & 63 & 47 & 69 & $68(76)$ & 76 & $81(87)$ \\
\hline PHV & 61 & 37 & 71 & $69(76)$ & 74 & $84(88)$ \\
\hline SLCV & 61 & 49 & 65 & $61(68)$ & 74 & $79(85)$ \\
\hline PYMV & 61 & 55 & 66 & $66(74)$ & 76 & $83(88)$ \\
\hline ACMV-Ke & 46 & 44 & 47 & $34(43)$ & 50 & $51(46)$ \\
\hline MYMV & 45 & 42 & 46 & $31(42)$ & 51 & $48(53)$ \\
\hline ICMV & 44 & 43 & 40 & $30(41)$ & 51 & $46(53)$ \\
\hline
\end{tabular}

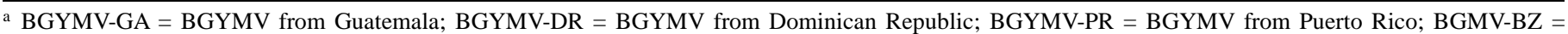
BGMV from Brazil; BDMV = Bean dwarf mosaic virus; $\mathrm{BCMoV}=$ Bean calico mosaic virus; ToMoV = Tomato mottle virus; $\mathrm{TLCrV}=$ Tomato leaf crumple virus; $\mathrm{SiGMV}=$ Sida golden mosaic virus; AbMV = Abutilon mosaic virus $;$ TGMV = Tomato golden mosaic virus; $\mathrm{PHV}=$ Pepper huasteco virus; SLCV = Squash leaf curl virus; PYMV = Potato yellow mosaic virus; ACMV-Ke = African cassava mosaic virus from Kenya; MYMV = Mung bean yellow mosaic virus; ICMV = Indian cassava mosaic virus. Total = comparison made with the complete nucleotide sequence of DNA-B. Numbers in parentheses are percent aa similarities. 
BGYMV-MX DNA-B (MX-B) developed severe golden mosaic symptoms (data represent means of three independent experiments with six seedlings per experiment). Interestingly, the symptom phenotype of the pseudorecombinants (i.e., the intensity of the mosaic and degree of stunting and distortion) was associated with
A

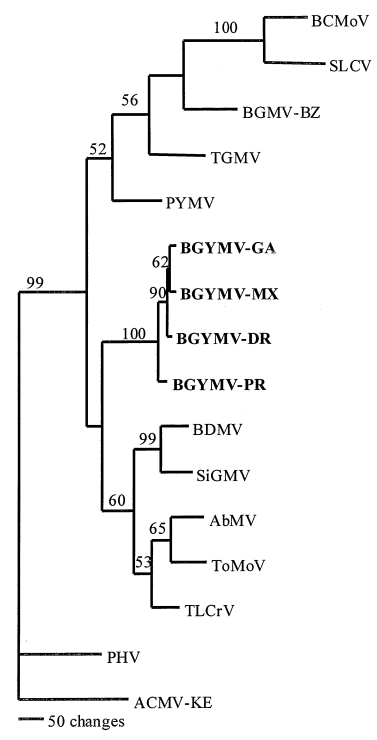

B

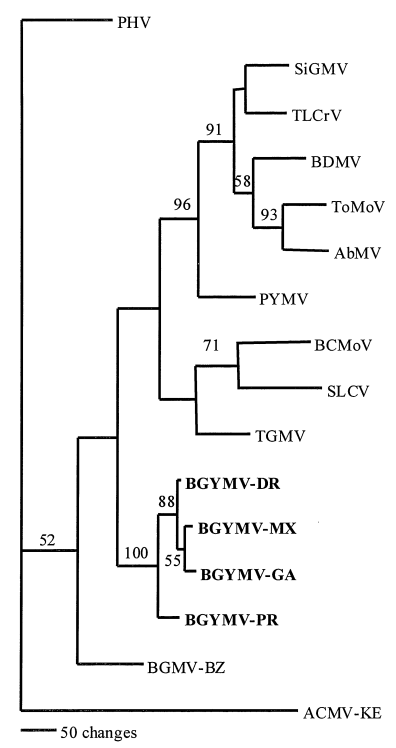

Fig. 1. Phylogenetic consensus trees showing the relationship of Bean golden yellow mosaic virus from Chiapas, Mexico (BGYMV-MX) with other begomoviruses based on alignments of $\mathbf{A}, \mathrm{AC} 1$ open reading frame (ORF) and B, BC1 ORF nucleotide sequences. Phylogenetic analyses were performed with PAUP (Phylogenetic Analysis Using Parsimony) version 4.0b3a for Macintosh using heuristic search. Branch strengths were evaluated by constructing 100 trees in a bootstrap analysis by step-wise addition at random. Bootstrap values (>50\%) are shown above the horizontal line. Horizontal lines are in proportion to the number of nucleotide differences between branch nodes. BGYMV strains are shown in bold letters. the source of the DNA-B component. Thus, plants infected by the GA-A/MX-B pseudorecombinant showed more extensive chlorosis and leaf distortion, whereas plants infected by the MX-A/GA-B pseudorecombinant showed larger areas of dark green and less extensive leaf distortion.

BGYMV-MX/BGYMV-DR pseudorecombinants were infectious, but in an asymmetric manner. The MX-A and BGYMV-DR DNA-B (DR-B) pseudorecombinant was highly infectious in bean when inoculated by particle bombardment (16 of 17 bombarded plants developed symptoms; mean of three independent experiments with six seedlings per experiment) and induced symptoms that were similar to, but slightly more severe than, BGYMV-DR. In contrast, the BGYMV-DR DNA-A (DR-A)/MX-B pseudorecombinant was less infectious ( 9 of 17 bombarded plants developed symptoms), and induced chlorosis and mild to moderate leaf distortion symptoms in infected trifoliolate leaves that were similar to, but milder than, symptoms induced by BGYMV-MX. Thus, the symptom phenotype mapped to the DNA-B component for the BGYMV-MX/BGYMV-DR pseudorecombinants.

The TLCrV DNA-A (TL-A)/MX-B PR was infectious in bean plants when inoculated by particle bombardment or agroinoculation and induced moderate vein clearing and epinasty symptoms in infected trifoliolate leaves (Table 3 ). The most severe symptoms induced by this pseudorecombinant were in plants inoculated by particle bombardment. The TL-A/MX-B pseudorecombinant was efficiently sap-transmitted from bean plant-to-bean plant (data not shown). $N$. benthamiana plants agroinoculated with the TL-A/MX-B were symptomless, with the exception of a single plant that showed mild epinasty and leaf crumpling. The reciprocal combination, MX-A/TLCrV DNA-B (TL-B), did not induce symptoms in bean or $N$. benthamiana plants (Table 3 ).

DNA-A and DNA-B were detected by PCR analyses in all plants tested that developed symptoms after inoculation with BGYMV-MX (beans), TLCrV (beans and N. benthamiana), or the TL-A/MX-B pseudorecombinant (beans and one $N$. benthamiana plant) (Table 3). Furthermore, restriction enzyme digestion analysis of these fragments with SpeI (cleaves only the BGYMV-

TABLE 3. Infectivity of Bean golden yellow mosaic virus from Mexico (BGYMV-MX), Bean dwarf mosaic virus (BDMV), Tomato leaf crumple virus (TLCrV), and pseudorecombinants made between the components of these begomoviruses in Phaseolus vulgaris (cv. Topcrop) seedlings inoculated by particle bombardment or agroinoculation and in Nicotiana benthamiana plants inoculated by agroinoculation; and detection of DNA-A and DNA-B components by polymerase chain reaction $(\mathrm{PCR})$ analysis ${ }^{\mathrm{a}}$

\begin{tabular}{|c|c|c|c|c|c|c|c|c|c|}
\hline \multirow[b]{3}{*}{ Inoculum $^{b}$} & \multicolumn{6}{|c|}{ P. vulgaris $\mathrm{cv}$. Topcrop } & \multirow{2}{*}{\multicolumn{3}{|c|}{$\begin{array}{l}N \text {. benthamiana } \\
\text { Agroinoculation }\end{array}$}} \\
\hline & \multicolumn{3}{|c|}{ Particle bombardment } & \multicolumn{3}{|c|}{ Agroinoculation } & & & \\
\hline & Symptoms & DNA-A & DNA-B & Symptoms & DNA-A & DNA-B & Symptoms & DNA-A & DNA-B \\
\hline BDMV & $20 / 20 * * *$ & $5 / 5$ & $5 / 5$ & $8 / 8 * *$ & $2 / 2$ & $2 / 2$ & $8 / 8 * *$ & $2 / 2$ & $2 / 2$ \\
\hline MX-A + BD-B & $0 / 20$ & $\overline{0 / 20}$ & $\overline{0 / 20}$ & $0 / 8$ & $0 / 8$ & $0 / 8$ & $0 / 8$ & $0 / 8$ & $0 / 8$ \\
\hline$B D-A+M X-B$ & $0 / 21$ & $0 / 21$ & $0 / 21$ & $0 / 8$ & $0 / 8$ & $0 / 8$ & $0 / 8$ & $6 / 8$ & $0 / 8$ \\
\hline Control & $0 / 16$ & $\underline{0 / 7}$ & $\underline{0 / 7}$ & $0 / 8$ & $\underline{0 / 2}$ & $\underline{0 / 2}$ & $0 / 8$ & $\underline{0 / 2}$ & $\underline{0 / 2}$ \\
\hline MX-A + TL-B & $0 / 12$ & $0 / 12$ & $0 / 12$ & $0 / 14$ & $\overline{2 / 14}$ & $0 / 14$ & $0 / 12$ & $2 / 12$ & $0 / 12$ \\
\hline TL-A + MX-B & $12 / 12 * *$ & $12 / 12$ & $12 / 12$ & $11 / 14 * *$ & $11 / 14$ & $11 / 14$ & $1 / 12 *$ & $1 / 12$ & $11 / 12$ \\
\hline Control & $0 / 12$ & $\underline{0 / 3}$ & $\underline{0 / 3}$ & $0 / 10$ & $0 / 10$ & $0 / 10$ & $0 / 12$ & $0 / 12$ & $0 / 12$ \\
\hline BDMV & $12 / 12 * * *$ & $\underline{3 / 3}$ & $\underline{3 / 3}$ & $17 / 18^{* * *}$ & $\underline{8 / 8}$ & $\underline{8 / 8}$ & $12 / 12 * *$ & $7 / 7$ & $7 / 7$ \\
\hline TLCrV & $12 / 12 * * *$ & $\overline{3 / 3}$ & $\overline{3 / 3}$ & $17 / 18^{* *}$ & $\overline{6 / 6}$ & $\overline{6 / 6}$ & $12 / 12 * * *$ & $\overline{7 / 7}$ & $\overline{7 / 7}$ \\
\hline BD-A + TL-B & $0 / 12$ & $0 / 12$ & $\overline{0 / 12}$ & $0 / 18$ & $\overline{3 / 1} 8$ & $\overline{0 / 18}$ & $0 / 12$ & $1 \overline{1 / 12}$ & $0 / 12$ \\
\hline
\end{tabular}

${ }^{a} P$. vulgaris data represent totals of three independent experiments; $N$. benthamiana data represent totals of two independent experiments. Number of infected plants (i.e., the presence of disease symptoms or detection of the appropriate DNA component by PCR analysis)/total number of plants inoculated or sampled. Symptom severity is indicated as follows: no asterisk $=$ symptomless; $*=$ mild symptoms; $* *=$ moderate symptoms; $* * *=$ severe symptoms. Symptoms were recorded at 14 days post inoculation. Underlined values indicates that only a subset of symptomatic and negative control plants were tested for the presence of DNA-A and DNA-B by PCR using degenerate primers.

${ }^{b}$ BGYMV-MX, BGYMV-MX DNA-A and DNA-B; BDMV, BDMV DNA-A and DNA-B; MX-A, BGYMV-MX DNA-A; MX-B, BGYMV-MX DNA-B; BD-A, BDMV DNA-A; BD-B, BDMV DNA-B; TLCrV, TLCrV DNA-A and DNA-B; TL-A, TLCrV DNA-A; TL-B, TLCrV DNA-B. Control consisted of gold particles alone (particle bombardment) or injection of culture media alone (agroinoculation). 
MX DNA-A and DNA-B fragments) and SacI (cleaves only the TLCrV DNA-A and DNA-B fragments) confirmed the presence of the inoculated components in selected BGYMV-MX-, TLCrV-, and MX-A/TL-B-infected bean or $N$. benthamiana plants.

Symptomless BGYMV-MX infections (DNA-A and DNA-B) were detected in many of the agroinoculated $N$. benthamiana plants (Table 3), which is consistent with the symptomless phenotype of BGYMV-GA in this host (31). For other pseudorecombinant $x$ host combinations in which symptomless infections were found, the DNA-A component was only detected in a number of plants. In agroinoculated $N$. benthamiana plants, TL-A infections were detected in 11 of 12 plants. For the MX-A/TL-B pseudorecombinant, no infections were detected in beans inoculated by particle bombardment, whereas MX-A infections were detected in a small number of agroinoculated bean ( 2 of 14) and $N$. benthamiana ( 2 of 12) plants. These results suggest that in these pseudorecombinant combinations, TL-A (alone) is more infectious than MX-A in $N$. benthamiana.

BGYMV-MX/BDMV and BDMV/TLCrV pseudorecombinants did not induce symptoms in common bean when introduced by particle bombardment or by agroinoculation, nor in agroinoculated $N$. benthamiana plants (Table 3 ). When evaluated for infection by PCR, TL-A and BD-A infections were detected in a small number of bean plants agroinoculated with the BDMV/TLCrV pseudorecombinants, but not in those agroinoculated with the BGYMVMX/BDMV pseudorecombinants. More DNA-A infections were detected in $N$. benthamiana plants agroinoculated with the BDMV/TLCrV pseudorecombinants and the BD-A/MX-B pseudorecombinant (11 of 12 for BD-A/TL-B, 10 of 12 for TL-A/BD$\mathrm{B}$ and 11 of 12 for TL-A/MX-B) than in plants agroinoculated with MX-A/TL-B ( 2 of 12). These results indicate that when delivered by agroinoculation in these pseudorecombinant combinations, TL-A and BD-A but not MX-A (alone) are highly infectious in $N$. benthamiana, whereas none of these components (alone) are highly infectious in common bean.

Bean germ plasm screening. Common bean germ plasm representing five out of the six races comprising the two major common bean gene pools (Mesoamerican and Andean) were inoculated with BGYMV-MX by three different methods: sap-inoculation, particle bombardment, and agroinoculation. Irrespective of the inoculation method, the highest infection rates and most severe symptoms were observed in the Andean germ plasm compared with the Mesoamerican germ plasm (Table 4), although infected plants of all of the germ plasm tested developed some degree of symptoms. Resistance to BGYMV-MX infection was detected among much of the Mesoamerican germ plasm based upon reduced disease incidence and symptom severity (Table 4). In addition, there were differences in the response of Mesoamerican germ plasm to BGYMV-MX depending on the inoculation method. When agroinoculated with BGYMV-MX, all Mesoamerican germ plasm had low rates of infectivity (average of $6 \%$ infection), and all but cv. Othello were rated as resistant. Higher rates of infectivity and disease ratings (i.e., many were rated as intermediate) were obtained with sap-inoculation (average of $41 \%$ infection) and particle bombardment (average of $40 \%$ infection) (Table 4). Improved BGYMV-resistant materials developed by the Centro Internacional de Agricultura Tropical (CIAT) Regional and Mexican Bean Breeding Programs (e.g., cvs. DOR 500, Negro Inifap, and Negro Tacana) showed a very high level of resistance when agroinoculated ( $0 \%$ infection; all rated as resistant) or sapinoculated $(9,20$, and 5\% infection, respectively; all rated as resistant). However, when inoculated by particle bombardment, these cultivars. had higher rates of infection $(50,64$, and $67 \%$, respectively; all rated as intermediate) (Table 4).

\section{DISCUSSION}

Squash blot hybridization and PCR analysis with degenerate primers established that a bipartite begomovirus was associated with bean golden mosaic in Chiapas, Mexico, and it was identified as an isolate/strain of BGYMV (type II BGMV) based on DNA sequence analyses and sap-transmissibility. Conclusive evidence that this BGYMV causes golden mosaic disease came from development of symptoms, indistinguishable from those observed in field-collected leaves, in bean seedlings bombarded or agroinoculated with infectious DNA-A and DNA-B clones. These

TABLE 4. Reaction of selected common bean (Phaseolus vulgaris L.) germ plasm to Bean golden yellow mosaic virus from Mexico (BGYMV-MX) following inoculation by three different methods ${ }^{\mathrm{a}}$

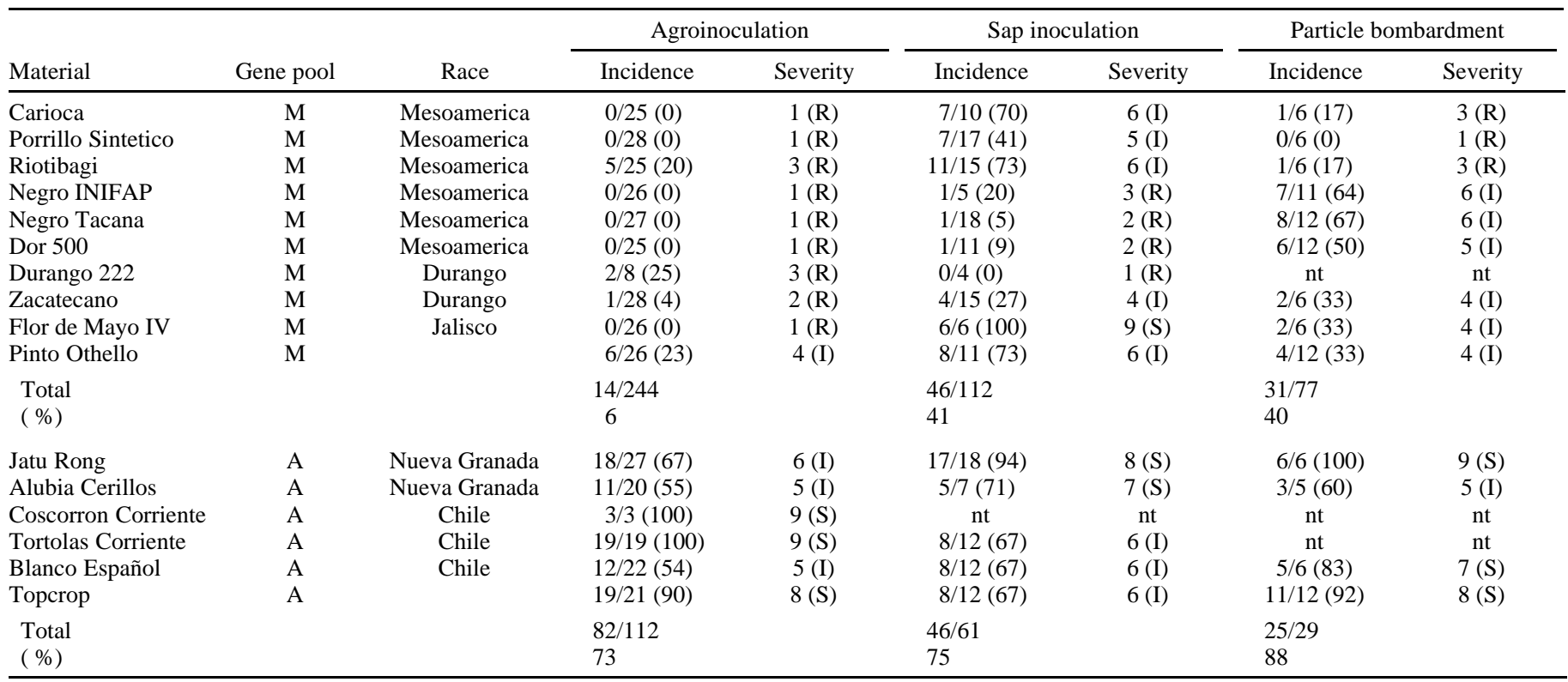

a Agroinoculation data represent totals of three independent experiments; sap-transmission and particle bombardment data represent total of one experiment. $\mathrm{M}=$ Mesoamerican gene pool; $\mathrm{A}=$ Andean gene pool. Number of infected plants (i.e., the presence of disease symptoms or detection of the appropriate DNA component by PCR analysis)/total number of plants inoculated or sampled. This is also presented as a percentage of total plants infected (in parentheses). Disease severity rating system ranging from 1 to 9 , where 1,2 , and $3=$ resistant (R); 4, 5, and $6=$ intermediate (I); and 7, 8, and $9=$ susceptible (S); (CIAT, 1987). $\mathrm{nt}=$ not tested. Cvs. Pinto Othello and Topcrop were the control cultivars for each major gene pool. 
results are consistent with (i) the characteristic golden mosaic symptoms observed in the samples from Chiapas, and (ii) the fact that golden mosaic in Guatemala is caused by BGYMV-GA (7).

However, these results did not establish whether BGYMV from Chiapas is an isolate of a previously characterized BGYMV strain (e.g., BGYMV-GA) or a distinct strain. Several BGYMV strains have been characterized (e.g., BGYMV-GA, -DR, and -PR), and these differ in nucleotide sequence and biological properties, such as symptom phenotype or properties of infectious pseudorecombinants $(7,17)$. In contrast, isolates of a given BGYMV strain have a high degree of sequence identity $(>95 \%)$ in the most variable regions of the genome ( $\mathrm{HV}$ region), possess similar biological properties, and often occur in the same geographical region $(8,17)$. Based on these criteria, BGYMV from Chiapas seems to represent a distinct BGYMV strain because of (i) sequence divergence in the HV region of DNA-B and (ii) distinct biological properties (i.e., symptom phenotype and properties of pseudorecombinants formed with other BGYMV strains). In recognition of these differences and its geographical origin, BGYMV from Chiapas was named BGYMV-MX. The BGYMVs infecting bean leaf samples from the four fields in Chiapas had nearly identical HV region sequences and, thus, would represent isolates of BGYMV-MX.

Infectious pseudorecombinants are usually formed between DNA components of isolates or strains of a given bipartite begomovirus or between very closely related species $(7,9,11,16,20-22$, $25,33,35)$. The ability to form infectious BGYMV-MX/BGYMVGA and BGYMV-MX/BGYMV-DR pseudorecombinants provided further evidence that BGYMV-MX is an isolate/strain of BGYMV. Furthermore, the distinct symptom phenotypes induced by these BGYMVs, with the correlation between symptom phenotype of the pseudorecombinant and the source of the DNAB component, established that biological differences exist among these BGYMVs. The results of these experiments also established that BGYMV-MX was more closely related to BGYMV-GA than to BGYMV-DR because the BGYMV-MX/BGYMV-GA pseudo- recombinants were symmetric in infectivity and pathogenicity, whereas the BGYMV-MX/BGYMV-DR pseudorecombinants were asymmetric. These differences may be due to the greater $\mathrm{CR}$ sequence identity between MX-A/GA-B (94\%) and GA-A/MX-B (90\%) compared with MX-A/DR-B (88\%) and DR-A/MX-B $(86 \%)$ (Table 5). These results are also consistent with (i) a previous report showing that BGYMV-GA/BGYMV-DR pseudorecombinants are asymmetric (7), (ii) results of the phylogenetic analyses showing that BGYMV-GA is more closely related to BGYMV-MX than is BGYMV-DR (Fig. 1), and (iii) the geographic proximity of Chiapas, Mexico and Guatemala.

The infectivity of TL-A/MX-B pseudorecombinant in bean was unexpected, even though BGYMV-MX and TLCrV infect beans and come from Mexico, because they are not closely related (i.e., they are in different phylogenetic clusters, Fig. 1; 30). Furthermore, the TL-A and MX-B CRs are only 68\% identical and have different Rep protein high affinity binding sites (TL-A = AGGGG and MX-B = TGGAG) and other repeated CR sequences (Table 5). A possible explanation for the infectivity of the TL-A/MX-B pseudorecombinant was that intermolecular recombination occurred, resulting in the TL-A and MX-B components having the same CRs. This was previously demonstrated for a pseudorecombinant generated between ToMoV DNA-A and BDMV DNA-B (22). However, restriction enzyme digestion analyses of TL-A and MX-B CR fragments, PCR amplified from TL-A/MX-B-infected bean plants, failed to reveal evidence of such an intermolecular recombination event (data not shown). This also suggests that the TL-A Rep protein can recognize and direct the replication of a DNA-B component with a highly divergent CR. The asymmetric infectivity of the BGYMV-MX/TLCrV pseudorecombinants (i.e., the MX-A/TL-B pseudorecombinant was not infectious) is consistent with reports for other pseudorecombinants generated between distinct begomovirus species (e.g., BDMV/ToMoV pseudorecombinants, 16; SiGMV/AbMV pseudorecombinants, 14; and Cabbage leaf curl virus/SLCV pseudorecombinants, 20). The reason for the asymmetry in the BGYMV-MX/TLCrV pseudore-

TABLE 5. Comparison of partial common region (CR) nucleotide sequences and repetitive elements of Bean golden yellow mosaic virus from Mexico (BGYMV-MX), Guatemala (BGYMV-GA), and the Dominican Republic (BGYMV-DR) and Tomato leaf crumple virus (TLCrV) and Bean dwarf mosaic virus (BDMV), and infectivity of pseudorecombinants made between the cloned DNA components of these begomoviruses

\begin{tabular}{|c|c|c|c|c|}
\hline $\mathrm{PRs}^{\mathrm{a}}$ & $\begin{array}{c}\text { CR identity } \\
(\%)\end{array}$ & $\begin{array}{l}\text { Inverted conserved } \\
\text { element }\end{array}$ & $\begin{array}{ll}\text { Conserved } & \text { Conserved } \\
\text { element } & \text { element }\end{array}$ & Infectivity ${ }^{\mathrm{b}}$ \\
\hline$\overline{\mathrm{MX}-\mathrm{A}}$ & & TCTCCAAATGAGTTTGCGAGTGT. CTCCAATC & TGCAATTGGAG. ACTGGAGTACAATATATA & \\
\hline$G A-B$ & 94 & TCTCCAAATGAGT"TTGCGAGTGT. CTCCAAT & TGCAATTGGAG. ACTGGAGTACAATATATA & $18 / 18$ \\
\hline$D R-B$ & 88 & TCTCCALTCGAGTTCt TGAGTGT.CTCCAT T & TGCAATTGGAG. ACTGGAGTACAATATATA & $16 / 17$ \\
\hline$B D-B$ & 71 & aCTCCAgTTGAGTT. ....... асTCCAAT & TtCtATTGGAGt AtTGGAGT actTAaATA & $0 / 22$ \\
\hline $\mathrm{TL}-\mathrm{B}$ & 60 & atTtttgTaataagaGgG.GTGTaCTCCGAT & atgttTTGGgGt AaaGGgG. ACAATATATA & $0 / 14$ \\
\hline$M X-B$ & & TCTCCAATTGAGTTTGCGAGTGT.CTCCGAT & TGCAATTGGAG . ACTGGAGTACAATATATA & \\
\hline$G A-A$ & 90 & TCTCCAAATGAGTTTGCGAGTGT. СTCCAAT & TGCAATTGGAG . ACTGGAGTACAATATATA & $18 / 18$ \\
\hline$D R-A$ & 86 & ctTCCgAATGgGTTTGCGAGTGT. CTCCAAT & TECAATTGGAG. ACTGGAGTACAATATATA & $9 / 17$ \\
\hline$B D-A$ & 74 & aCTCCAgTTGAGTT. . . . . . . aCTCCAAT & TtCtATTGGAGt AtTGGAGT actTATATA & $0 / 22$ \\
\hline TL-A & 68 & caTtttgTaAtaagatGgGTGTaCTCCGAT & atgttTTGGgGt AaaGGgG. ACAATATATA & $11 / 14$ \\
\hline $\mathrm{TL}-\mathrm{A}$ & & ttgTaAtaagatGgGTGTaCTCCGAT & atgttTTGGgGt AaaGGgG.ACAATATATA & \\
\hline $\mathrm{BD}-\mathrm{B}$ & 73 & aCTCCAgTTGAGTT......... ACTCCAAT & TtCtATTGGAGt AtTGGAGTLaCtTAaATA & $0 / 18$ \\
\hline $\mathrm{TL}-\mathrm{B}$ & & atrtttgTaataagaGgG.GTGTaCTCCGAT & atgttTTGGgGtAaaGGgG. ACAATATATA & \\
\hline $\mathrm{BD}-\mathrm{A}$ & 77 & aCTCCAgTTGAGTT. ........ астCCAAT & TtCtATTGGAGt AtTGGAGTtactTATATA & $0 / 18$ \\
\hline
\end{tabular}

${ }^{a}$ PR = pseudorecombinants between BGYMV-MX DNA-A (MX-A) and DNA-B of BGYMV-GA (GA-B), BGYMV-DR (DR-B), BDMV (BD-B), or TLCrV (TL-B); PRs between the BGYMV-MX DNA-B component (MX-B) and DNA-A of BGYMV-GA (GA-A), BGYMV-DR (DR-A), BDMV (BD-A), or TLCrV (TL-A); and PRs between TL-A and BD-B and BD-A and TL-B.

${ }^{\mathrm{b}}+=$ infectious PRs generated; $-=$ infectious PRs not generated. Number of infected plants (i.e., the presence of disease symptoms or detection of the appropriate DNA components by PCR analysis)/total number of plants inoculated.

${ }^{c}$ In pairwise comparisons between the CRs of the two DNA components of a PR, capital letters represent nucleotides that are identical with those of the BGYMV-MX DNA-A or DNA-B CR and small letters represent nucleotides that are different; bold letters represent nucleotides of the conserved CR elements that are identical with those of BGYMV-MX, and $\ldots$ = a gap in the sequence. 
combinants may be due to the MX-A/TL-B CRs being less identical $(60 \%)$ than the TL-A/MX-B CRs $(68 \%)$ or that the Rep protein high affinity binding sites of MX-A and TL-B are more different (TGG $\underline{A G}$ vs. $\underline{A A G G G}$, nt differences are underlined) than those of MX-B and TL-A (TGGAG vs. AGGGG). However, it is unlikely that these differences are solely responsible for the asymmetry, because the BDMV CR sequences and repeated elements are more identical to those of BGYMV-MX than are those of TLCrV, yet the BGYMV-MX/BDMV pseudorecombinants were not infectious (Table 5). Alternatively, the asymmetry of the BGYMV-MX/TLCrV pseudorecombinants may relate to the DNA-B component of the pseudorecombinant, as previously suggested for the BDMV/ToMoV pseudorecombinants (22). Thus, the infectivity of the TL-A/MX-B pseudorecombinant in bean (but not $N$. benthamiana) may be due to MX-B being extremely well adapted to common bean. In this scenario, the efficient expression or function of the BGYMV-MX BV1 and BC1 movement proteins may allow for efficient movement of the TL-A/MX-B pseudorecombinant in bean, but not in $N$. benthamiana, a host to which BGYMV-MX is not well adapted (Table 5; 31). The DNA-A component could also contribute to the infectivity of the TLA/MX-B pseudorecombinant. It has been postulated that TLCrV evolved from SiGMV (30), which appears to be a quasispecies composed of a mixture of genetically diverse DNA components (9). Thus, the SiGMV Rep protein, as well as that of TL-A, may have the capacity to recognize and direct the replication of genetically diverse DNA-B components. Irrespective of the mechanisms involved, the TL-A/MX-B pseudorecombinant represents one of the few examples of an infectious pseudorecombinant generated between begomovirus species from distinct phylogenetic clusters. This suggests that pseudorecombination may be a potential mechanism for evolution among more distantly related begomoviruses than previously suspected (22).

Disease resistance is the most desirable management strategy for bean golden mosaic. In many cases, it is desirable to develop inoculation methods that do not involve the whitefly vector. Three vector-independent BGYMV-MX inoculation methods were evaluated with a range of bean germ plasm, including a number of golden mosaic-resistant lines generated through conventional breeding programs. Regardless of the inoculation method used, germ plasm from the Andean gene pool (races Nueva Granada and Chile) was considerably more susceptible to BGYMV-MX infection than germ plasm from the Mesoamerican gene pool (representing races Mesoamerica, Durango, and Jalisco). This is in agreement with previous reports $(19,27)$.

None of the Mesoamerican germ plasm tested in the present study were immune to BGYMV-MX infection, but many showed high levels of resistance including cv. Porrillo Sintetico, which has been used as a source of golden mosaic resistance $(27,29)$. The wide range of responses to BGYMV infection in segregating populations derived from crosses with cv. Porrillo Sintetico has been used to suggest that this resistance is controlled by multiple (quantitative) genes (29). This is consistent with the high level of resistance (reduced disease incidence and symptom severity), but lack of immunity, detected in this cultivar in the present study. In an attempt to increase the level of golden mosaic resistance and broaden the genetic base of new BGYMV resistant materials, a strategy of crosses between germ plasm from different common bean races has been employed (29). Our results showing BGYMV resistance in Mesoamerican germ plasm from different races support the use of this strategy.

The three inoculation methods gave similar results for the Andean germ plasm, but differences were observed for the Mesoamerican germ plasm. For example, the new golden mosaic resistant/tolerant cultivars developed by CIAT and the Mexican National Programs (e.g., cvs. DOR 500, Negro Inifap, and Negro Tacana) were highly resistant when inoculated by agroinoculation or sap-transmission, but had an intermediate rating when inocu- lated by particle bombardment. This suggests that the level of resistance in these cultivars is related to the growth stage at which plants are inoculated. In the case of particle bombardment, hypocotyls of 4-day-old seedlings are inoculated and primary leaves develop symptoms. In contrast, 10 to 12-day-old plants are used for agroinoculation and sap-inoculation and primary leaves (already formed) do not develop symptoms, reflecting the later stage of growth at which these plants were inoculated. It has also been previously reported that older plants are less susceptible than younger plants to geminivirus infection; for example, increasing the age at which bean plants were sap-inoculated with BGYMVGA resulted in a corresponding increase in resistance (28).

The lack of infection observed in Mesoamerican but not Andean germ plasm when inoculated by agroinoculation may provide insight into the resistance mechanisms in Mesoamerican germ plasm. It has been suggested that agroinoculation establishes localized infections in phloem cells in and around the site of inoculation and that these infected cells provide inoculum for systemic infection (23). A recent study of resistance to BDMV infection in the Mesoamerican cv. Othello revealed that resistance was associated with a hypersensitive response in the phloem (36). It is possible that a similar response in Mesoamerican germ plasm agroinoculated with BGYMV-MX prevented systemic infection. This resistance mechanism may be less effective for the other inoculation methods.

In summary, BGYMV-MX infection of common bean is a function of the genotype, experimental inoculation method, and stage of growth at which plants are inoculated. It is important to determine which inoculation method best reflects the capacity of a material to resist BGYMV infection under field conditions (i.e., when inoculated by viruliferous whiteflies). A practical advantage of the agroinoculation method is the ease with which large numbers of plants can be inoculated, but it will be important to ascertain whether the results obtained for agroinoculation under the controlled environmental conditions used in this study will be similar under field conditions.

\section{ACKNOWLEDGMENTS}

This research was funded in part by a CONACYT (Mexico) doctoral fellowship to E. R. Garrido-Ramirez and a grant from Seminis Vegetable Seed Company to R. L. Gilbertson.

\section{LITERATURE CITED}

1. Blair, M. W., Bassett, M. J., Abouzid, A. M., Hiebert, E., Polston, J. E., McMillan, R. T., Jr., Graves, W., and Lamberts, M. 1995. Occurrence of bean golden mosaic virus in Florida. Plant Dis. 79:529-533.

2. Bird, J., Sanchez, J., Rodriguez, R. L., and Julia, F. J. 1975. Rugaceous (whitefly-transmitted) viruses in Puerto Rico. Pages 3-26 in: Tropical Diseases of Legumes. J. Bird and K. Maramorosch, eds. Academic Press, New York.

3. Brown, J. K. 1997. The biology and molecular epidemiology of the geminiviridae subgroup III. G. Stacey and N. T. Keen, eds. Plant Microbe Interact. 2:125-195.

4. Brown, J. K., Ostrow, K. M., Idris, A. M., and Stenger, D. C. 1999. Biotic, molecular, and phylogenetic characterization of bean calico mosaic virus, a distinct Geminivirus species with affiliation in the squash leaf curl virus cluster. Phytopathology 89:273-280.

5. Centro Internacional de Agricultura Tropical. 1987. Standard System for the Evaluation of Bean Germplasm. A. van Schoonhoven and M. A. Pastor-Corrales, eds. Centro Internacional de Agricultura Tropical, Cali, Colombia.

6. Costa, A. S. 1965. The whitefly-transmitted viruses of bean in Sao Paulo, Brazil. FAO Plant Prot. Bull. 13:121-130.

7. Faria, J. C., Gilbertson, R. L., Hanson, S. F., Morales, F. J., Ahlquist, P., Loniello, A. O., and Maxwell, D. P. 1994. Bean golden mosaic geminivirus type II isolates from the Dominican Republic and Guatemala: Nucleotide sequences, infectious pseudorecombinants, and phylogenetic relationships. Phytopathology 84:321-329.

8. Faria, J. C., and Maxwell, D. P. 1999. Variability in geminivirus isolates associated with Phaseolus spp. in Brazil. Phytopathology 89:262-268.

9. Frischmuth, T., Engel, M., Lauster, S., and Jeske, H. 1997. Nucleotide 
sequence evidence for the occurrence of three distinct whitefly-transmitted, Sida-infecting bipartite geminiviruses in Central America. J. Gen. Virol. 78:2675-2682.

10. Galvez, G. E., and Morales, F. J. 1989. Whitefly-transmitted viruses. Pages 379-406 in: Bean Production Problems in the Tropics. 2nd ed. H. F. Schwartz and M. A. Pastor-Corrales, eds. Centro Internacional de Agricultura Tropical, Cali, Colombia.

11. Garrido-Ramirez, E. R., and Gilbertson, R. L. 1996. Molecular characterization of bean golden mosaic geminivirus (BGMV) from Chiapas, Mexico. (Abstr.) Phytopathology 86(suppl.):S17.

12. Garrido-Ramirez, E. R., and Gilbertson, R. L. 1998. First report of tomato mottle geminivirus infecting tomatoes in Yucatan, Mexico. Plant Dis. 82:592.

13. Gilbertson, R. L., Faria, J. C., Ahlquist, P., and Maxwell, D. P. 1993. Genetic diversity in geminiviruses causing bean golden mosaic disease: The nucleotide sequence of the infectious cloned DNA components of a Brazilian isolate of bean golden mosaic geminivirus. Phytopathology 83: 709-715.

14. Gilbertson, R. L., Faria, J. C., Hanson, S. F., Morales, F. J., Ahlquist, P., and Maxwell, D. P. 1991. Cloning of the complete DNA sequence of four bean-infecting geminiviruses and determining their infectivity by electric discharge particle acceleration. Phytopathology 81:980-985.

15. Gilbertson, R. L., Hidayat, S. H., Martinez, R. T., Leong, S. A., Faria, J. C., Morales, F., and Maxwell, D. P. 1991. Differentiation of bean infecting geminiviruses by nucleic acid hybridization probes and aspects of bean golden mosaic in Brazil. Plant Dis. 75:336-342.

16. Gilbertson, R. L., Hidayat, S. H., Paplomatas, E. J., Rojas, M. R., Hou, Y. M., and Maxwell, D. P. 1993. Pseudorecombination between infectious cloned DNA components of tomato mottle and bean dwarf mosaic geminiviruses. J. Gen. Virol. 74:23-31.

17. Gilbertson, R. L., Rojas, M. R., Russell, D. R., and Maxwell, D. P. 1991. Use of asymmetric polymerase chain reaction and DNA sequencing to determine genetic variability of bean golden mosaic geminivirus in the Dominican Republic. J. Gen. Virol. 72:2843-2848.

18. Hanley-Bowdoin, L., Settlage, S. B., Orozco, B. M., Nagar, S., and Robertson, D. 1999. Geminiviruses: Models for plant DNA replication, transcription, and cell cycle regulation. Crit. Rev. Plant Sci. 18:71-106.

19. Hidayat, S. H. 1991. The construction and application of DNA probes for the detection of bean dwarf mosaic geminivirus. M.S. thesis. University of Wisconsin, Madison.

20. Hill, J. E., Strandberg, J. O., Hiebert, E., and Lazarowitz, S. G. 1998. Asymmetric infectivity of pseudorecombinants of cabbage leaf curl virus and squash leaf curl virus: Implications for bipartite geminivirus evolution and movement. Virology 250:283-292.

21. Hofer, P., Engel, M., Jeske, H., and Frischmuth, T. 1997. Host range limitation of a pseudorecombinant virus produced by two distinct bipartite geminiviruses. Mol. Plant-Microbe Interact. 10:1019-1022.

22. Hou, Y. M., and Gilbertson, R. L. 1996. Increased pathogenicity in a pseudorecombinant bipartite geminivirus correlates with intermolecular recombination. J. Virol. 70:5430-5436.

23. Hou, Y. M., Paplomatas, E. J., and Gilbertson, R. L. 1998. Host adaptation and replication properties of two bipartite geminiviruses and their pseudorecombinants. Mol. Plant-Microbe Interact. 11:208-217.

24. Howarth, A. J., Caton, J., Bossert, M., and Goodman, R. M. 1985. Nucleotide sequence of bean golden mosaic virus and a model for gene regulation in geminiviruses. Proc. Natl. Acad. Sci. USA 82:3572-3576.

25. Lazarowitz, S. G., and Lazdins, I. B. 1991. Infectivity and complete nucleotide sequence of the cloned genomic components of a bipartite squash leaf curl geminivirus with a broad host range phenotype. Virology 180:58-69.

26. McBride, K. E., and Summerfelt, K. R. 1990. Improved binary vector for Agrobacterium-mediated plant transformation. Plant Mol. Biol. 14: 269-276.

27. Morales, F. J., and Niessen, A. I. 1988. Comparative response of selected Phaseolus vulgaris germ plasm inoculated artificially and naturally with bean golden mosaic virus. Plant Dis. 72:1020-1023.

28. Morales, F. J., Niessen, A., Ramirez, B., and Castaño, M. 1990. Isolation and partial characterization of a geminivirus causing bean dwarf mosaic. Phytopathology 80:96-101.

29. Morales, F. J., and Singh, S. P. 1993. Breeding for resistance to bean golden mosaic virus in an interracial populations of Phaseolus vulgaris L. Euphytica 67:59-63.

30. Paplomatas, E. J., Patel, V. P., Hou, Y. M., Noueiry, A. O., and Gilbertson, R. L. 1994. Molecular characterization of a new sap-transmissible bipartite genome geminivirus infecting tomatoes in Mexico. Phytopathology 84:1215-1224.

31. Petty, I. T. D., Miller, C. G., Meade-Hash, T. J., and Schaffer, R. L. 1995. Complementable and noncomplementable host adaptation defects in bipartite geminiviruses. Virology 212:263-267.

32. Rojas, M. R., Gilbertson, R. L., Russell, D. R., and Maxwell, D. P. 1993. Use of degenerate primers in the polymerase chain reaction to detect whitefly-transmitted geminiviruses. Plant Dis. 77:340-347.

33. Stanley, J., Townsend, R., and Curson, S. J. 1985. Pseudorecombination between cloned DNAs of two isolates of cassava latent virus. J. Gen. Virol. 66:1055-1061.

34. Timmermans, M. C. P., Das, O. P., and Messing, J. 1994. Geminiviruses and their uses as extrachromosomal replicons. Annu. Rev. Plant Physiol. Plant Mol. Biol. 45:79-112.

35. Von Arnim, A., and Stanley, J. 1992. Determinants of tomato golden mosaic virus symptom development located on DNA-B. Virology 186: 286-293.

36. Wang, H. L., Sudarshana, M. R., Gilbertson, R. L., and Lucas, W. J. 1999. Analysis of cell-to-cell and long-distance movement of a bean dwarf mosaic geminivirus-green fluorescent protein reporter in host and nonhost species: Identification of sites of resistance. Mol. Plant-Microbe Interact. 12:345-355. 